\title{
Interactive comment on "Physico-chemical characterization of urban aerosols from specific combustion sources in West Africaat Abidjan in Côte d'Ivoire and Cotonou in Benin in the frame of DACCIWA program" by Aka Jacques Adon et al.
}

Anonymous Referee \#2

Received and published: 17 August 2019

This manuscript describes a dataset that measured and characterized aerosol particles in Abidjan and Cotonou during the DACCIWA project. The dataset explores aerosol mass and composition, during two dry seasons and two wet seasons. This is an important and rich dataset. The manuscript does address relevant scientific questions and is within the scope of ACP. 
This is rich dataset with a lot of detailed information. As structured currently, I find it difficult to read and remember all the linkages and trends. I do understand this is in part due to the large amount of information in the dataset. However, I do find it detracts from the quality of the manuscript and thus, the impact of this dataset. I found it difficult to review the robustness of the conclusions, as the results that supported such conclusions (e.g. wood burning at ADF) are across so many different sections and the linkages between them (e.g. total, EC and OC masses) are not clearly stated. I was wondering, if the article was restructured, if it would help. One way I thought of was what if the main findings are presented (i.e. PM, EC, OC, dust mass) first at a very high level, and then the results and discussion moves to a full discussion of the results site by site. As can be seen in my comments, in the Results section I struggled with making connections between these for the sites (i.e. PM total mass, EC, OC, etc), and what that "means" for each site. As such, I was wondering if a change in structure to a full discussion of site by site, and then comparisons across sites would assist in the structure. I thought in this way the points of each site could be made all at once, as all of the data to support these conclusions would be presented at once. I do believe it is clear in my comments on the pdf that I am recommending that some change in the structure or reporting of the results is necessary; this restructuring is just a suggestion of a way to address these concerns.

As the results and discussion are so detailed with so much information, I would recommend the conclusion is more a synthesis. I would recommend that it is more concise and highlights what these results all "mean" when taken as a whole. I do find that synthesis is missing some from the current version.

I would recommend that the title is changed. The results show that the aerosols are not just from combustion sources, and thus the title is misleading. https://www.atmos-chem-phys-discuss.net/acp-2019-406/acp-2019-406-RC2- 
supplement.pdf

Interactive comment on Atmos. Chem. Phys. Discuss., https://doi.org/10.5194/acp-2019-406, 2019.

Interactive

comment 